\title{
ESTUDO DE CONFIGURAÇÕES DE PROCESSO DE COGERAÇÃO APLICADO EM UMA ESTAÇÃO DE TRATAMENTO DE EFLUENTES
}

\author{
F. S. LIMA' ${ }^{1}$, V. M. C. ALVES ${ }^{1}$, P. L. BARROS ${ }^{1}$ e A. C. B. de ARAUJO' \\ ${ }^{1}$ Universidade Federal de Campina Grande, Departamento de Engenharia Química \\ E-mail para contato: felipe.lima@eq.ufcg.edu.br
}

\begin{abstract}
RESUMO - Devido à importância que o saneamento tem para a qualidade de vida humana, há um crescente enfoque em tecnologias utilizadas para o tratamento de dejetos biológicos, principalmente aquelas que dizem respeito a estações de tratamento de efluentes. E com o advento de simuladores, o estudo e desenvolvimento de tais tecnologias ficou consideravelmente cômodo, especialmente quando se busca maneiras de redução de custos que envolvem a operação destas estações de tratamento. A proposta apresentada por este trabalho é a implementação de modelos de equipamentos, no software Matlab/Simulink®, que são comumente utilizados na indústria de forma que seja possível a redução de gastos envolvidos com a operação de uma planta de tratamento de resíduos biológicos, já previamente modelada no mesmo software, através da queima de biogás produzido por esta planta. Ao final da modelagem foi obtido como resultado uma redução do requerimento energético da estação de tratamento em até $48 \%$. Dessa forma, conclui-se que a metodologia aqui apresentada é viável para a cogeração de tal estação.
\end{abstract}

\section{INTRODUÇÃO}

Estações de tratamento de esgoto são essenciais para o mundo atual devido ao benefício substancial que estas trazem à qualidade de vida humana principalmente por meio do aspecto de saneamento, pela redução de emissões de poluentes (e.g. compostos ricos em nitrogênio, enxofre, fósforo, metais pesados, ácidos orgânicos e inorgânicos, etc.) que estão presentes nos rejeitos gerados inerentes à atividade humana, e também para o reaproveitamento de água, recurso este que está se tornando escasso com o passar dos anos.

O estudo que aqui será apresentado se baseia no trabalho publicado por Jeppsson et al. (2011), já implementado no software Simulink/Matblab®, que contém um manual de referência para o layout de uma planta de estação de tratamento de lodo ativado com informações sobre modelos de simulação, informação de carga de influentes a serem tratados, procedimentos de teste e demais critérios de avaliação.

No entanto, o trabalho de Jeppsson et al. (2011) não referencia ou propõe maneiras de redução de gastos energéticos com a operação da planta (e.g. areação de biorreatores, misturadores, bombas e aquecimento). Sendo assim, este estudo consiste na avaliação de uma 
possível configuração de equipamentos utilizados na indústria que permitam a redução destes gastos operacionais através da queima do biogás que é gerado por esta estação de tratamento.

\section{FUNDAMENTAÇÃO TEÓRICA}

O diagrama de processo da planta proposta por Jeppson et al. (2011) está disposto na figura 1. O biogás que é utilizado na queima vem do biodigestor anaeróbico localizado na parte inferior direita da figura.

Figura 1 - Diagrama de fluxo de processo da estação de tratamento

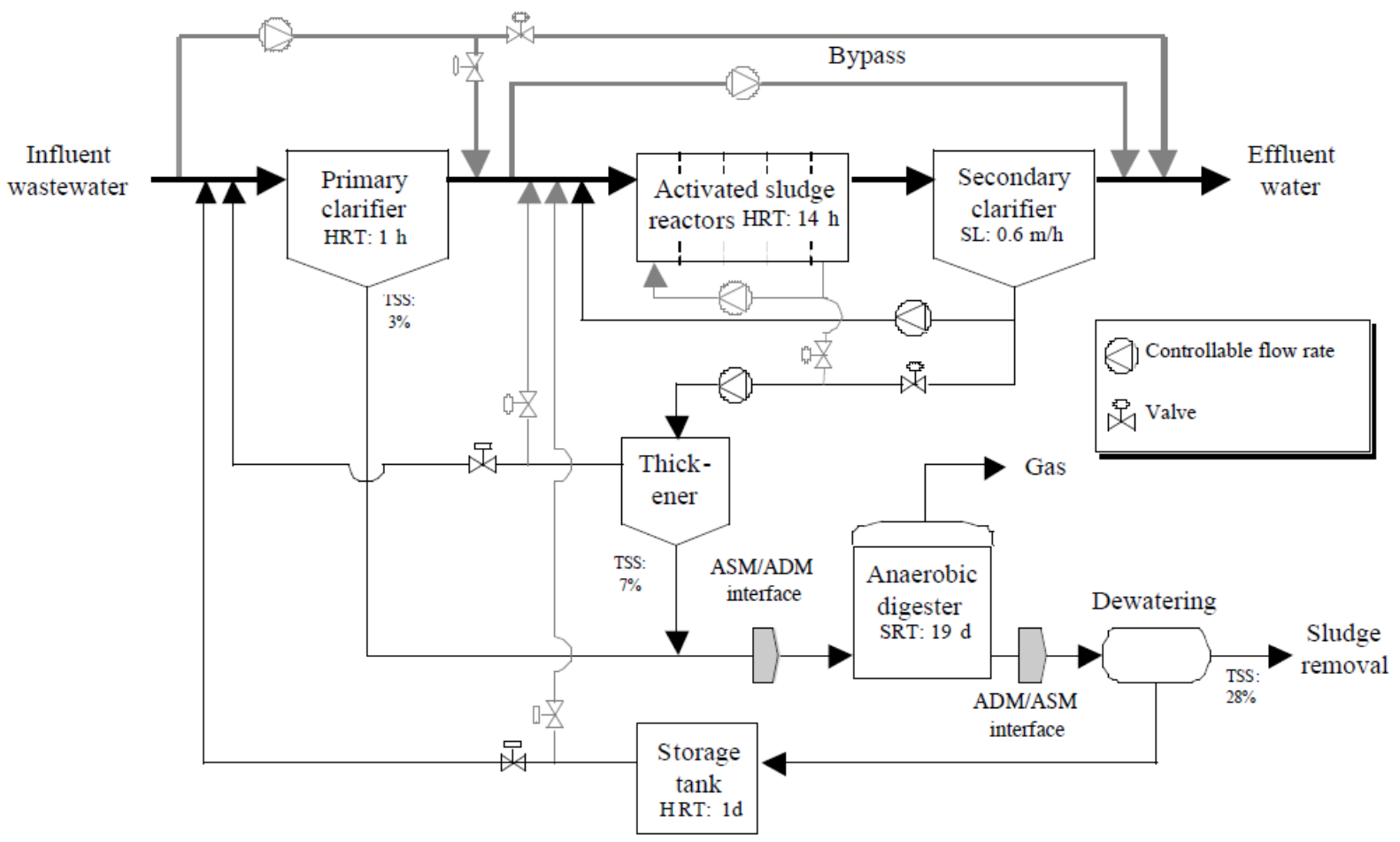

\subsection{Modelagem do compressor}

Sabendo que um fluido ao sofrer processo de expansão ou compressão que seja reversível e adiabático, então este processo é isentrópico (Smith et al., 2000). A eficiência de um compressor isentrópico é calculada pela equação 1 a seguir:

$\eta_{C}=\frac{W_{\text {Isentrópicoo }}}{W_{\text {Eixo }}}$

Sabendo que, para um processo em estado estacionário, o balanço de energia é descrito pela equação 2: 
$\Delta H+\frac{\Delta u^{2}}{2}+g \Delta z=Q+W$

Considerando que os termos de variação de energia potencial, cinética e calor são desprezíveis, então a equação 2 fica:

$W_{\text {Eixo }}=\Delta H$

O mesmo se aplica para o trabalho de eixo isentrópico. A variação de entropia em um gás ideal é dada pela equação 3 (Smith et al., 2000).

$\Delta S=\left\langle C_{p}\right\rangle \ln \frac{T_{2}}{T_{1}}-R \ln \frac{P_{2}}{P_{1}}$

\subsection{Modelagem da fornalha}

Considerando a condição de combustão incompleta do metano:

$$
\mathrm{CH}_{4(g)}+\frac{3}{2} \mathrm{O}_{2(g)} \rightarrow \mathrm{CO}_{(g)}+2 \mathrm{H}_{2} \mathrm{O}_{(g)}
$$

Aplicando a equação 2 com as mesmas considerações utilizadas para o compressor, e que não há trabalho sendo realizado pelo sistema, tem-se que:

$\Delta \mathrm{H}=\Delta \mathrm{H}_{\mathrm{R}}^{0}+\Delta H_{298}^{0}+\Delta H_{p}^{0}=0$

Com a equação 5 em função da temperatura, e aplicando métodos numéricos para solução de equações não lineares, é possível obter a temperatura de chama adiabática que é produzida pela queima do metano.

Limites de flamabilidade e efeitos de diluição com adição de inerte: Misturas que envolvem combustíveis dispersos tais como gases/vapores inflamáveis e ar só atingem o ponto de ignição caso o valor de concentração do combustível se encontre entre limites inferiores e superiores de concentração de combustível estabelecidos experimentalmente. Para um modelo de fornalha mais preciso é necessário realizar o estudo de limites de flamabilidade e o efeito que a presença de $\mathrm{CO}_{2}$ que é produzido juntamente com metano no biodigestor da estação de tratamento.

\subsection{Turbinas}

A modelagem das turbinas faz uso das equações 2, 3 e 4 com as mesmas considerações aplicadas no compressor. A diferença está no conceito de eficiência, já que turbinas usam o processo de expansão (inverso da compressão) que é descrito pela equação 6.

$\eta_{T}=\frac{W_{\text {Eixo }}}{W_{\text {Isentrópico }}}$ 
De acordo com o trabalho publicado por Martínez et al. (2011), a maior temperatura de operação de turbinas comumente usadas na indústria é de $1700{ }^{\circ} \mathrm{C}$, portanto, para manter a operação o modelo aqui apresentado em níveis aceitáveis, a temperatura do gás que entra na turbina será estipulada para $1500{ }^{\circ} \mathrm{C}$.

\subsection{Caldeiras}

No processo de recuperação energética as caldeiras são utilizadas para extrair a energia residual do gás, ainda quente que sai da turbina a gás, e assim gerar mais energia com o uso de turbinas a vapor. Neste caso, a modelagem deste equipamento é feita considerando ele como um trocador de calor simples. Não foi levado em conta a geometria do trocador ou material de construção, apenas é considerado que toda a carga térmica do gás é trocada com a água dentro do sistema como é descrito na equação 7.

$-\dot{Q}_{\text {Gás }}=\dot{Q}_{\text {Água }}$

\subsection{Bombas}

Utilizando conceitos da primeira e segunda lei da termodinâmica, o trabalho isentrópico realizado por uma bomba é calculado pela equação 8 .

$$
W_{\text {Isentrópico }}=\int_{P_{1}}^{P_{2}} d H=\int_{P_{1}}^{P_{2}} V d P=V\left(P_{2}-P_{1}\right)
$$

Para calcular o trabalho de eixo desta bomba utiliza-se a equação 8 em conjunto com a equação 1 , desde que a eficiência da bomba seja conhecida.

\section{METODOLOGIA}

O diagrama do processo (PFD) que mostra a configuração montada está representada na figura 2. Este diagrama foi implementado no software Simulink® acoplado ao modelo da estação de tratamento feito por Jeppsson et al. (2011).

Figura 2 - Diagrama do processo de cogeração que foi implementado no software Simulink®

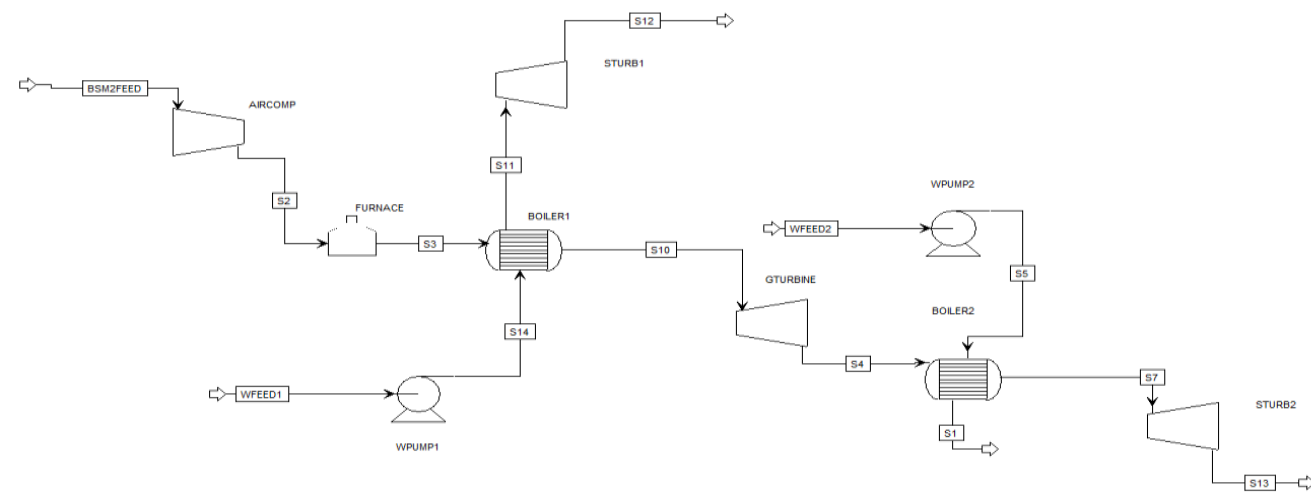


No diagrama da figura 2 tem-se a alimentação do processo de cogeração, que é a saída do biodigestor presente na figura 1. Esta mistura contendo $\mathrm{CH}_{4}, \mathrm{CO}_{2}$ (e traços de vapor d'água e $\mathrm{H}_{2}$ ) é comprimida junto com ar em um compressor e injetada em uma fornalha. Os gases provenientes da queima passam por uma caldeira para gerar vapor de média pressão (10 bar e $500{ }^{\circ} \mathrm{C}$ ) para ser utilizado em uma turbina a vapor, estes gases com temperatura reduzida, porém ainda quentes o suficiente, são alimentados à uma turbina a gás. Os gases que saem da turbina a gás são resfriados em uma segunda caldeira para gerar mais vapor, que também é alimentado a outra turbina a vapor.

\section{RESULTADOS}

Toda energia aproveitável pelo processo de cogeração, isto é, a soma de toda energia produzida pelas três turbinas menos o que é consumido pelo compressor de ar e duas bombas, foi de 2488,2 kWh.dia ${ }^{-1}$. De acordo com o trabalho de Jeppsson et al. (2011), a estação de tratamento de efluentes requer $5210 \mathrm{kWh} \cdot \mathrm{dia}^{-1}$ que são gastos com aeração de tanques, bombeamento e misturadores.

Demais valores produzidos pelas turbinas e consumidos pelos demais equipamentos da estação de cogeração estão presentes na tabela 1 .

Tabela 1 - Valores de variáveis calculadas no processo de cogeração

\begin{tabular}{|c|c|c|c|}
\hline Equipamento & Variável & Valor & Unidade \\
\hline \multirow{2}{*}{ Turbina a gás } & $W_{\text {eixo }}$ & 3148,8 & kWh.dia ${ }^{-1}$ \\
\hline & $T_{2}$ & 1305 & Kelvin \\
\hline \multirow{2}{*}{$\begin{array}{l}\text { Turbina a vapor } \\
\text { (Primeira) }\end{array}$} & $W_{\text {eixo }}$ & 309,6 & kWh.dia ${ }^{-1}$ \\
\hline & $T_{2}$ & 560 & Kelvin \\
\hline \multirow{2}{*}{$\begin{array}{l}\text { Turbina a vapor } \\
\text { (Segunda) }\end{array}$} & $W_{\text {eixo }}$ & 748,8 & kWh.dia ${ }^{-1}$ \\
\hline & $T_{2}$ & 560 & Kelvin \\
\hline Compressor & $W_{\text {eixo }}$ & 1716 & kWh.dia ${ }^{-1}$ \\
\hline Bomba (Primeira) & $W_{\text {eixo }}$ & 0,9 & kWh.dia ${ }^{-1}$ \\
\hline Bomba (Segunda) & $W_{\text {eixo }}$ & 2,1 & kWh.dia ${ }^{-1}$ \\
\hline Fornalha & $T_{2}$ & 2101 & Kelvin \\
\hline
\end{tabular}




\section{CONCLUSÃO}

No que se refere a redução de requerimentos energéticos, este processo de recuperação energética é viável, tendo em vista que é possível a produção de $2488,2 \mathrm{kWh}$.dia ${ }^{-1}$ dos 5210 $\mathrm{kWh} \cdot \mathrm{dia}^{-1}$ que são consumidos com energia para operação da estação de tratamento, ou seja, uma redução de 47,7\%. Com isto, conclui-se que a metodologia aqui apresentada possui resultados satisfatórios e que pode ser utilizada em estudo futuros que envolvam o prospecto de recuperação energética em processos semelhantes ao aqui apresentado por meio de cogeração.

\section{NOMENCLATURA}

\begin{tabular}{cccc}
\multicolumn{4}{c}{ Variáveis } \\
\hline$\eta$ & Eficiência & $\Delta S$ & Variação entrópica \\
$W$ & Trabalho & $g$ & Gravidade \\
$\Delta H$ & Variação entálpica & $Q$ & Calor/Carga térmica \\
$\Delta u^{2}$ & Variação cinética & $P$ & Pressão \\
$\Delta z$ & Variação potencial gravitacional & $T$ & Temperatura \\
$\left\langle C_{p}\right\rangle$ & Capacidade calorifica especifica & $V$ & Volume \\
$R$ & Constante universal dos gases ideais & &
\end{tabular}

\begin{tabular}{cccc}
\multicolumn{4}{c}{ Subscritos } \\
\hline$C$ & Compressor & 1 & Entrada \\
$T$ & Turbina & 2 & Saída \\
$R$ & Reagentes & 298 & 298 Kelvins $\left(25^{\circ} \mathrm{C}\right)$ \\
$P$ & Produtos & &
\end{tabular}

Sobrescritos

$0 \quad$ Entalpia de referência

\section{REFERÊNCIAS}

JEPPSSON, U.; PONS, M. N. NOPENS; I., ALEX. J.; BENEDETTI. L.; COPP. J.; GERNAEY. K. V.; STEYER. J. P.; VANROLLEGHEM. P. Benchmark simulation model no 2 (BSM2). Lund, 2011. 99p.

MARTÍNEZ, F. R.; MARTÍNEZ, A. R.; VELAZQUEZ, M. T.; DIEZ, P. Q.; ESLAVA, G. T.; FRANCIS, J. A. Evaluation of the Gas Turbine Inlet Temperature with Relation to the Excess Air. Energy and Power Engineering, v. 03, n. 04, p. 517-524, 2011.

SMITH, J. M; VAN NESS, H. C.; ABBOTT, M. M. Introduction to Chemical Engineering Thermodynamics. 6. ed. New York: McGraw-Hill, 2000. 